\title{
'SWEAT TEST' RESULTS IN NORMAL PERSONS OF DIFFERENT AGES COMPARED WITH FAMILIES WITH FIBROCYSTIC DISEASE OF THE PANCREAS
}

\author{
BY \\ CHARLOTTE M. ANDERSON and MAVIS FREEMAN \\ From the Clinical Research Unit, Royal Children's Hospital, Melbourne
}

(RECEIVED FOR PUBLICATION APRIL 11, 1960)

Many workers have confirmed the original observation of Darling, Di Sant'Agnese, Perera and Andersen (1953) that sweat sodium and chloride levels in children with fibrocystic disease of the pancreas are three to four times higher than those found in normal children. The reason for this has not yet been defined, but the difference is so clear in children that the 'sweat test' has become one of considerable diagnostic value.

However, the normal variation of sweat sodium and chloride levels in adults and in persons of varying age from childhood into adolescence and adult life has not been so clearly defined. Despite the absence of sound data of this type there is an increasing volume of literature in which the authors interpret small variations in these levels as an indication of abnormality in the groups of persons concerned. For instance, Di Sant'Agnese, Darling, Perera and Shea (1953) and Smoller and Hsia (1959) state that a proportion of parents and siblings of children with fibrocystic disease of the pancreas have somewhat raised sodium and chloride levels and that this indicates their carrier or heterozygous state; Hsia, Driscoll, Greenberg, Lee and Lanoff (1958) state that patients with allergies, particularly asthma, show higher levels than other children; Wood, Fishman, Reemtsma, Barker and Di Sant' Agnese (1959) state that some adult patients with chronic chest disease such as chronic obstructive pulmonary emphysema show raised levels and should be considered 'formes frustes' of fibrocystic disease of the pancreas.

Earlier work (Anderson and Freeman, 1958), in which a small group of parents and siblings were compared each with a group of normal adults and children failed to show any difference between the sweat sodium and chloride levels in the corresponding groups, but it did indicate that the levels in adults tended to be higher than those in children. This work has been extended to include groups of greater numbers, primarily to delineate the sweat sodium and chloride levels throughout life. These levels have then been compared at the corresponding ages with those obtained in larger groups of parents and siblings of patients with fibrocystic disease. The levels in children with chronic or recurrent chest disease, including asthma, have also been compared with those of children of similar ages free from chest illnesses.

\section{Materials and Method}

Method. Sweating was stimulated by an intradermal injection of mecholyl hydrochloride, as described in an earlier publication (Anderson and Freeman, 1958); $2 \mathrm{mg}$. mecholyl was injected intradermally on the forearm in adults and older children and a smaller dose in babies and young children. Sweat was collected for one hour.

Sodium was measured by flame photometry. This estimation can be accurately made in amounts of sweat as small as $\mathbf{5 0} \mathrm{mg}$., which was all that could be obtained from some very young infants. In the majority of instances at other ages, over $100 \mathrm{mg}$. was obtained. Chloride was determined by the method of Schales and Schales. Owing to the relative inaccuracy of titration when chloride levels are low and small amounts of sweat are collected, sodium levels are considered to be the most reliable. Therefore sodium figures only are presented in this paper. There would be no difference in the general pattern of results if chloride figures were also presented but for the sake of clarity and accuracy they are not detailed here.

In our previous publication the level of $70 \mathrm{mEq} / / 1$. was chosen as the upper limit of normal and the lower limit of the fibrocystic level, but greater experience has shown that the vast majority of non-fibrocystic children under 15 years give values below $60 \mathrm{mEq}$./1. sodium, whilst a small percentage of fibrocystic values lie between 60 and $70 \mathrm{mEq}$. $/ 1$. Consequently a dividing level at $60 \mathrm{mEq}$./1. is now taken but all results between 60 and $70 \mathrm{mEq} . / 1$. are checked.

Clinical Material. The following seven groups were studied:

1. One hundred patients with fibrocystic disease of the pancreas; these were all patients cared for medically 
TABLE 1

COMPARISON OF SWEAT SODIUM LEVELS IN CHILDREN WITH FIBROCYSTIC DISEASE OF PANCREAS WITH THOSE OF THEIR SIBLINGS, CONTROL CHILDREN AND CHILDREN WITH CHEST DISORDERS

\begin{tabular}{|c|c|c|c|c|c|c|c|c|c|c|}
\hline \multirow{2}{*}{ Group } & \multirow{2}{*}{ No. } & \multicolumn{9}{|c|}{ Sweat Sodium Levels (mEq./1.) } \\
\hline & & $0-20$ & $20-30$ & $30-40$ & $40-50$ & $50-60$ & $60-70$ & $70-80$ & $80-90$ & $>90$ \\
\hline $\begin{array}{ll}\text { 'Fibrocystics' .. } & \ldots \\
\text { Controls } & \ldots \\
\text { Chronic chest } & \text { disease } \\
\text { Siblings } & \ldots\end{array}$ & $\begin{array}{r}100 \\
100 \\
100 \\
61\end{array}$ & $\begin{array}{r}0 \\
28 \\
23 \\
8\end{array}$ & $\begin{array}{r}2 \\
27 \\
31 \\
28\end{array}$ & $\begin{array}{r}0 \\
25 \\
28 \\
34\end{array}$ & $\begin{array}{r}0 \\
11 \\
15 \\
12\end{array}$ & $\begin{array}{r}3 \\
6 \\
1 \\
15\end{array}$ & $\begin{array}{l}7 \\
3 \\
2 \\
3\end{array}$ & $\begin{array}{r}11 \\
0 \\
0 \\
0\end{array}$ & $\begin{array}{r}16 \\
0 \\
0 \\
0\end{array}$ & $\begin{array}{r}61 \\
0 \\
0 \\
0\end{array}$ \\
\hline
\end{tabular}

Numbers represent \% of each group.

by one of us (C.M.A.) during a three-year period. The diagnosis was confirmed by clinical history and examination, and by at least one other test, i.e. the demonstration of pancreatic achylia or deficiency, or of steatorrhoea by laboratory techniques.

2. One hundred children up to 15 years of age used as controls; some of these children showed no organic disease and were tested purely as controls. The others were referred for diagnosis and showed conditions such as coeliac disease, steatorrhoea or failure to thrive. No child with subacute, recurrent or chronic chest symptoms is included in this group. Stools were always examined for excess fat in those who had failed to thrive and all children with steatorrhoea were shown to have normal pancreatic enzymes.

3. One hundred children up to 15 years of age who showed symptoms of subacute, recurrent, or chronic chest disease, but no digestive upsets or clinical evidence of pancreatic deficiency; these children comprise, first, a group, of whom the majority were infants, who were referred for a diagnostic sweat test because they had recurrent attacks of pneumonia or bronchitis; second, a group of patients with proven suppurative bronchiectasis all treated for a number of years by Dr. Howard Williams of the Royal Children's Hospital Chest Clinic; and third, a smaller group of children with chronic asthma who were also patients of the chest clinic.

4. Sixty-one siblings of the patients with fibrocystic disease of the pancreas; these were all under 15 years of age, were healthy, had grown normally and were within normal limits when examined clinically but did not undergo any other test to exclude fibrocystic disease of the pancreas.

5. One hundred adults over 20 years of age with no known disease; these were personnel working in the hospital and relatives and friends of the Clinical Research Unit staff.

6. One hundred parents of the patients with fibrocystic disease of the pancreas; these were all over 20 years of age and did not complain of any persistent diarrhoea or chronic cough.

7. Forty-seven adolescents between 15 and 20 years with no known disease; these were young nurses, office workers, laboratory technicians and school children.

\section{Results}

All groups contained individuals of both sexes in roughly equal numbers, but no difference in sodium or chloride levels was noted between the sexes, although men usually produced a larger volume of sweat than women. Results are given with no further reference to sex.

Among the 100 whose diagnosis was considered to be that of fibrocystic disease of the pancreas and who were all under 15 years of age when first tested, all but five showed levels of sodium and chloride above $60 \mathrm{mEq}$./litre by the method employed. Sodium results are included in Table 1 where the actual number of children showing various levels are indicated. The two children whose sodium levels are between 20 and $30 \mathrm{mEq}$./ litre were tested twice with similar results. They show other characteristics of the disease, are sisters, have pancreatic achylia and persistent suppurative chest infection of the type so familiar in this disease. The three children with sodium levels between 50 and $60 \mathrm{mEq}$./litre all have chloride levels above $60 \mathrm{mEq}$./litre. These children were retested with similar findings in one and higher results in the other two. However, the results recorded are the first performed, as is so with all groups. It can be seen that $95 \%$ of sodium values are higher than 60 $\mathrm{mEq}$./litre, $61 \%$ being higher than $90 \mathrm{mEq}$./litre. Table 1 compares these results with the sodium figures obtained from the three other groups of children.

Among the 100 children up to 15 years of age who did not suffer from any chronic chest infection, allergy or pancreatic achylia, $97 \%$ of the sweat sodium values are below $60 \mathrm{mEq}$./litre with $80 \%$ below $40 \mathrm{mEq}$./litre. Among the 100 children with subacute or chronic chest disorders, $98 \%$ of sweat sodium values are below $60 \mathrm{mEq}$./litre with $82 \%$ below $40 \mathrm{mEq}$./litre, a scatter almost identical to that of children without chest symptoms. Among the 61 siblings of the patients with fibrocystic disease 59 or $97 \%$ were below $60 \mathrm{mEq}$./litre, 43 or $70 \%$ being below $40 \mathrm{mEq}$./litre.

Fig. 1 illustrates the results from the three groups of non-fibrocystic children giving a scatter according to age. The overall uniformity of scatter can be seen but as age progresses a somewhat upward trend in 


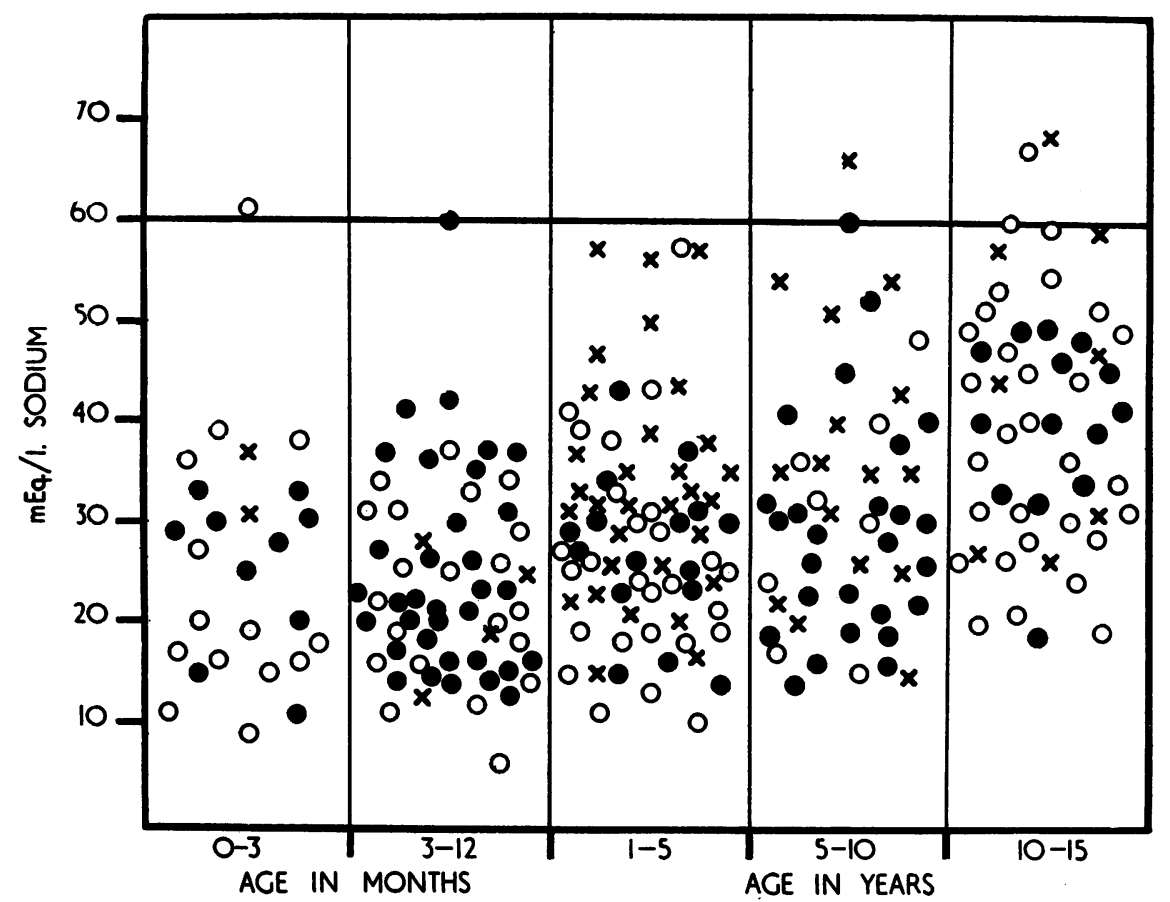

FIG. 1.-Sweat sodium levels in children of varying ages up to 15 years (the upper figure is included in each age group).

$\mathrm{O}=$ normal children; $\mathrm{O}=$ children with chronic chest diseases; $\mathrm{x}=$ siblings of children with fibrocystic disease of pancreas.

values occurs in all groups. Combining the three groups it can be seen that up to 12 months of age all but four of the results are below $40 \mathrm{mEq}$./litre, but after that all age groups show more results between 40 and $60 \mathrm{mEq}$./litre and in the 10-15 age group about $50 \%$ of the values are at that level. Therefore up to the level of puberty the majority of values are below $40 \mathrm{mEq}$./litre, but there is a tendency for values to increase in later childhood.

There is no difference at all between the scatter of results for children with or without chest illness of non-fibrocystic origin. Among the siblings there are rather more children in the older age groups, for instance, $90 \%$ of them are over 12 months compared with $40 \%$ of the other two groups combined. Taking this into account there is no significant difference between the results from the siblings and the other groups.

The results from the 100 normal adults (Table 2) and (Fig. 2) show a much wider scatter of results. A considerable number, $34 \%$, were $60 \mathrm{mEq}$./litre and higher and only $23 \%$ were below $40 \mathrm{mEq}$./litre, a contrast to the non-fibrocystic children. The 100 parents of the fibrocystic children (Table 2 and Fig. 2) show a similar wide scatter of results with $39 \%$ over $60 \mathrm{mEq} . /$ litre and $19 \%$ below $40 \mathrm{mEq} . /$ litre. Although a few more results from parents are in the higher levels, notably the $70-80 \mathrm{mEq}$./litre group, there is a wide scatter of results and above $80 \mathrm{mEq}$./litre a very similar number to the normal adults. There is therefore no significant difference between the two groups of adults, although they

TABLE 2

COMPARISON OF SWEAT SODIUM LEVELS IN 100 'NORMAL' ADULTS AND 100 PARENTS OF CHILDREN WITH FIBROCYSTIC DISEASE OF THE PANCREAS

\begin{tabular}{|c|c|c|c|c|c|c|c|c|c|c|}
\hline \multirow{2}{*}{ Group } & \multirow{2}{*}{ No. } & \multicolumn{9}{|c|}{ Sweat Sodium Levels (mEq./1.) } \\
\hline & & $0-20$ & $20-30$ & $30-40$ & $40-50$ & $50-60$ & $60-70$ & $70-80$ & $80-90$ & $>90$ \\
\hline $\begin{array}{l}\text { 'Normal' adults } \\
\text { Parents of children } \\
\text { with fibrocystic dis- } \\
\text { ease of the pancreas }\end{array}$ & $\begin{array}{l}100 \\
100\end{array}$ & 0 & 7 & 16 & 21 & 22 & 12 & 12 & 6 & 4 \\
\hline
\end{tabular}


differ significantly from the three groups of children up to 15 years.

The 47 normal adolescents between 15 and 20 years of age show results intermediate between those of the children and the adults with 11 or $24 \%$ above $60 \mathrm{mEq}$./litre and 13 or $27 \%$ below $40 \mathrm{mEq}$./ litre (Table 3 and Fig. 2).

Fig. 2 gives the scatter of results of children, adolescents, adults and parents and indicates clearly the gradual increase in levels with age, the greater number of higher results after puberty as well as the wide variation of values in adult life. Table 3 combines all the non-fibrocystic results illustrating again the upward trend of values with increasing age, and shows the percentage of each group giving values below $40 \mathrm{mEq}$./litre, between 40 and 60 $\mathrm{mEq}$./litre, and above $60 \mathrm{mEq}$./litre. From these
TABLE 3

COMPARISON OF SWEAT SODIUM LEVELS IN ALL GROUPS STUDIED TO SHOW INCREASING VALUES AT AND AFTER PUBERTY

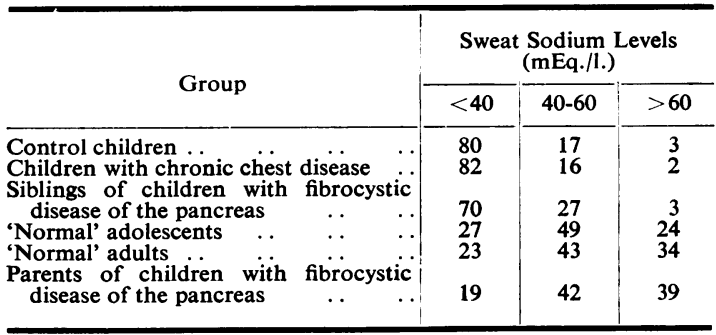

Numbers represent $\%$ in each group.

results it can be seen that about puberty and in adult life the level of $60 \mathrm{mEq}$./litre can no longer

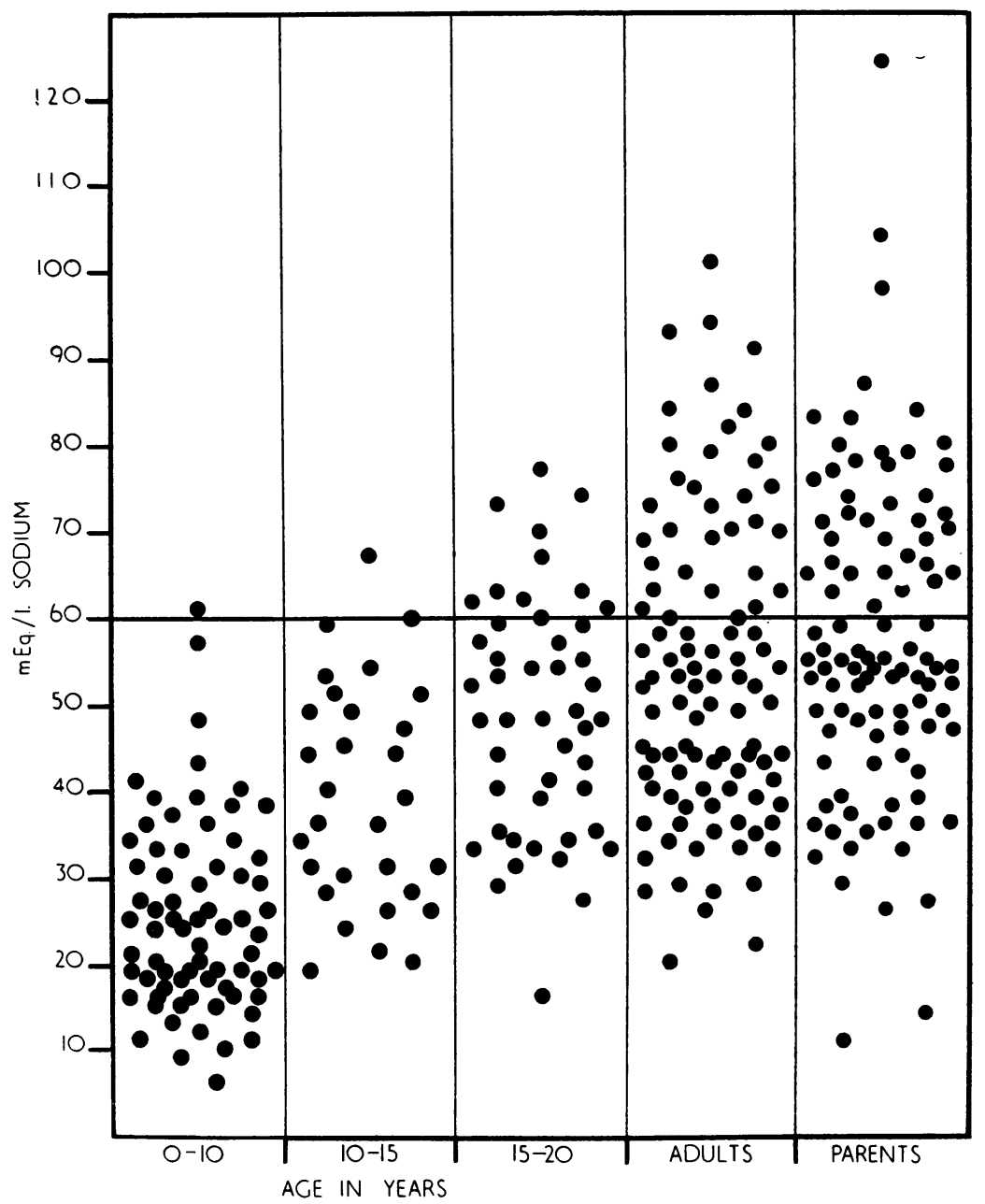

FIG. 2.-Comparison of sweat sodium levels in control children adolescents, adults and parents of children with fibrocystic disease of the pancreas (the upper figure is included in each age group). 
TABLE 4

INDIVIDUAL VARIATION IN SWEAT RATE AND COMPOSITION IN FOUR NORMAL ADULTS WITH CONSTANT MECHOLYL STIMULUS

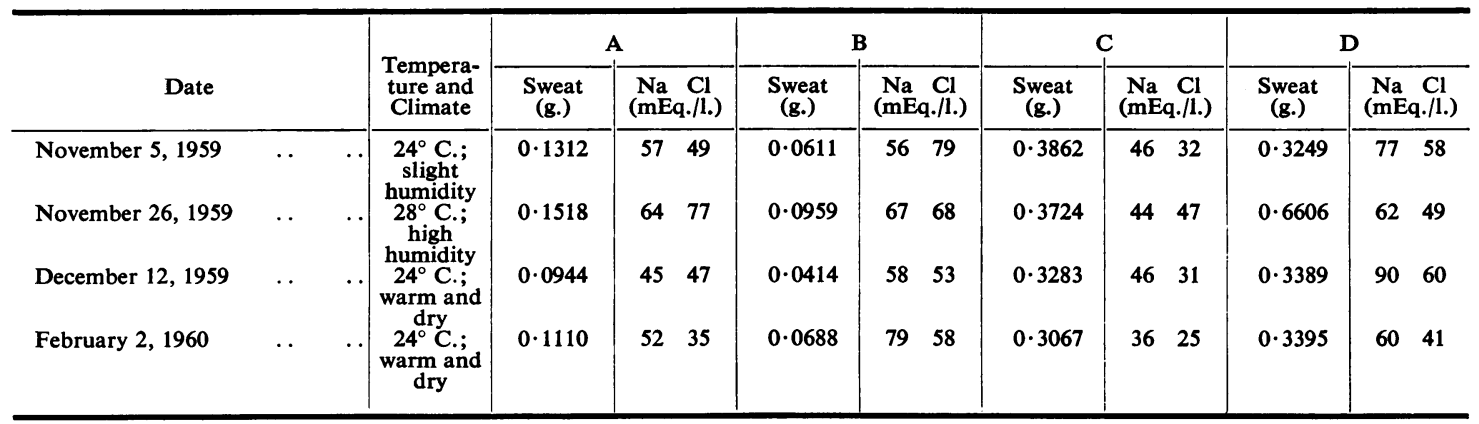

$A$ and $B$ are female. $C$ and $D$ are male.

be considered as the dividing level between a normal and an abnormal level of sweat sodium.

Normal adults included individuals of varying ages up to the seventh decade and parents up to the fifth decade, but an analysis of these into age groups did not reveal any significant difference in levels. The increase in values was gradual in later childhood, becoming greater at puberty, but did not progress further with old age.

Not only were the values from persons over the age of puberty likely to be higher, but results from individuals showed greater variation when repeated at intervals. To illustrate this variation four normal adults were tested at about monthly intervals and the results are recorded in Table 4. Here some indication is given of the climatic conditions of the day and amounts of sweat collected. Both sodium and chloride levels are indicated. This Table shows the considerable lability in sweat levels using as far as possible the same stimulus. No real correlation is seen with the climate, nor the volume of sweat and hence perhaps the rate, as the time of collection was constant.

Levels over $90 \mathrm{mEq}$./litre among the adults and parents were repeated if possible. There were seven individuals with values in this region. One male parent and one male adult were unavailable for retesting. Three of the other five showed lowered levels of retesting, although still above $60 \mathrm{mEq}$./litre. The remaining two, one female parent and one adult woman, showed consistent levels. The female parent, the only adult with a sodium level over $120 \mathrm{mEq}$./litre, was healthy but thin and had never had any chronic chest symptoms nor diarrhoea. A stool was normal in appearance and no fat globules were seen by microscopy. We believe this result to be a normal variant, but it is worthy of further investigation.
Chloride values are not recorded for reasons stated earlier, but the pattern of results in relation to age was very similar. $60 \mathrm{mEq}$./litre of chloride was still found to be the dividing line between 'fibrocystic' and 'non-fibrocystics' when considering children up to 15 years of age. In adults the sodium and chloride values did not approximate each other quite as closely as they did in children. Among the two groups of adults tested, i.e. 'normals' and 'parents', sodium figures were often slightly higher than chloride figures. However, this did not alter the comparison between the two groups of adults as there was still a comparable number of figures over $60 \mathrm{mEq}$./litre, for instance, $23 \%$ of normal adults and $25 \%$ of parents.

\section{Discussion}

Using a constant method of sweat stimulation and collection, levels of sweat sodium have been determined at various ages in childhood, adolescence and adult life. Fairly constant levels in infants and young children are found, but these levels rise slowly as age progresses and become very much more variable after puberty. Although the level of $60 \mathrm{mEq}$./litre of sodium can be said to be the upper limit of normal in the sweat of children under 15 years, such is not the case in adolescents and adults where many of the values are above this level. In all children under 15 who were tested, whether they are free from disease, suffer from chronic chest disease of non-fibrocystic origin, or are siblings of patients with fibrocystic disease, values are in the same range and $60 \mathrm{mEq}$./litre can be taken as the upper level. Taking into account the increasing values occurring after puberty there is also no difference in the pattern of results obtained from normal adults and from parents of patients with fibrocystic disease. 
The two latter observations are at variance with those reported by some other workers, notably Di Sant'Agnese et al. (1953), Di Sant'Agnese (1957, 1959), and Smoller and Hsia (1959) who consider that levels of sodium and chloride in the sweat of some parents and siblings are higher than normal from which they deduce that these individuals are carriers of the abnormal gene of fibrocystic disease; and Hsia et al. (1958) who consider that children with chronic or allergic chest disease show higher levels than normal children. Our results, using a much wider range of controls, show no evidence to support these views. It is difficult to reconcile these varying results, but there are some factors which can be discussed.

A possible criticism of our results is that the method of obtaining sweat is not a satisfactory one. Among workers in the field of sweat electrolytes in fibrocystic disease of the pancreas a variety of methods have been used to stimulate sweating, but these fall broadly into two classes: sweating stimulated by heat or by other chemical agents. Results recorded by Di Sant'Agnese and his group and Hsia and co-workers are those of heat sweat. In the present study the method of sweat stimulation by intradermal mecholyl has been chosen for reasons outlined in a previous publication (Anderson and Freeman, 1958). As pointed out in that paper, the levels of sodium and chloride in sweat obtained in this way may be somewhat higher, occasionally up to $20 \mathrm{mEq}$./litre, than in sweat obtained by heat stimulation. However, this choice of method does not significantly affect the results obtained in the present study because all tests were done in the same way and can therefore be compared with each other, although not necessarily with those of other workers.

It might be possible that heat sweat produces a different pattern of values. However, study of the literature relating to normal sweating reveals a wide divergence in the range of results of sodium and chloride obtained by many workers. Notable amongst these references are the review by Robinson and Robinson (1954) and the monograph on 'Human Perspiration' by Kuno (1956). The former authors state that the concentration of sodium chloride in thermal sweat is extremely variable and give a list of 10 references in which values varying from as high as 100 to $148 \mathrm{mEq}$./litre down to $5 \mathrm{mEq}$./litre are reported, all on supposedly normal individuals and mostly adults. Kuno lists three groups of workers who find values as divergent as 400 to $17 \mathrm{mg}$. $\%$ sodium. They both point out the numerous factors such as skin temperature, climatic conditions, dietary intake of salt, and adrenal cortical activity, which can affect these levels and
Kuno in particular mentions age, discussing a control mechanism which begins to act on the sweat centres about puberty. Therefore it seems that our results in adults obtained by mecholyl stimulation parallel in the main those of many other workers, who were not concerned with fibrocystic disease of the pancreas.

Precise knowledge of the physiological control of the concentration of electrolytes in sweat has not yet been obtained, but many factors apparently affect these concentrations. The results presented here support Kuno's statement that age may be one of the factors and that about puberty there may be some physiological alteration in the control mechanism, or the factors that influence the concentrations may be playing a greater part, perhaps the endocrine factors. In view of the confusion that exists regarding the precise limits of normal variation of sweat sodium and chloride concentration in adults and the limitations of knowledge regarding the physiological control of these electrolyte levels, it is unwise to draw conclusions from the rather minor differences which some workers have observed in a proportion of parents and siblings of patients with fibrocystic disease and in some patients with chronic chest disease. In the work of both Di Sant'Agnese's group and Hsia and co-workers small groups of control adults are mentioned, but no attention paid to variation over a wide range of age.

A study of the literature devoted to the sweat sodium and chloride levels in patients with fibrocystic disease of the pancreas shows that differing levels are given by several authors as the upper limit of normal. The original contribution of Darling et al. (1953) stated that $60-70 \mathrm{mEq}$./litre of sweat sodium or chloride in heat sweat was the dividing line between normal and abnormal, but in a recent publication from the same centre (Di Sant' Agnese, 1959) the figure of $50 \mathrm{mEq}$./litre is given without adequate explanation of the change. Similarly, $50 \mathrm{mEq}$./litre is the upper level stated by Hsia et al. (1958) whilst 70 to $80 \mathrm{mEq}$./litre is the figure given by Shwachman and Leubner (1955). As there is still such variation among workers regarding the upper limit of normal for heat sweat it does not seem reasonable to theorize over levels between 50 and $70 \mathrm{mEq}$./litre obtained in parents and siblings (Smoller and Hsia, 1959), children with allergic chest conditions (Hsia et al., 1958), or adults with chronic chest disease (Petersen, 1959).

The abnormal gene for fibrocystic disease of the pancreas appears to be a reasonably frequent one in the community and it might be argued that the adults and parents who showed values over $60 \mathrm{mEq}$./litre 
in this paper were all heterozygotes. However, between 30 and $40 \%$ of both groups of adults tested came into this category and not even the most enthusiastic geneticist has yet placed the carrier rate at this level. The majority opinion suggests that the incidence of this disease in communities of Caucasian origin is in the region of one in 1,000 live births (Carter, in Bodian, 1953; Childs, 1956) and consequently, as the former writer states, the carrier rate would be about one in 15 or $6.5 \%$.

If these higher results did indicate the carrier state then a proportion of siblings should show results in the same range, but in the data presented here they do not. Apart from the constant and clear difference between fibrocystic and non-fibrocystic children under 15 years of age there does not seem to be any other information relevant to fibrocystic disease of the pancreas than can at present be obtained from a study of the actual levels of sweat sodium and chloride, unless the reason for the varying and high levels found normally after puberty bears any relationship to the underlying defect in this disease.

As a consequence of the data presented here the determination of sweat sodium and chloride loses much of its value as a test for the diagnosis of fibrocystic disease of the pancreas in adults. We have already encountered difficulty in several adolescents and older persons who are suspected by certain clinical features of suffering from this disease. In these a very careful assessment of all features relevant to the disease should be made. As yet, there is insufficient evidence for the postulation of 'formes frustes' of the disease, but this will be discussed in more detail in a future publication.

The sweat abnormality or the abnormality of exocrine secretions in fibrocystic disease of the pancreas cannot yet be explained in basic terms, and until this can be done, slight abnormalities of sweat electrolytes should not be regarded as a genetic manifestation of the disease. Theorizing in this regard has preceded precise basic knowledge, and may give rise to misleading genetic counselling.

\section{Summary}

The range of sweat sodium and chloride levels obtained by stimulation with mecholyl in normal persons from birth to old age has been determined. A slight increase in concentration of these electrolytes has been found with increasing age in childhood. There is a greater increase and variation at and after puberty.

No difference has been observed in the results from
100 normal adults over 20 years of age and 100 parents of fibrocystic children.

No difference has been observed in the results from 61 healthy siblings of fibrocystic children and other children up to 15 years of age.

No difference has been observed in the results from 100 normal children and 100 children with chronic chest illness other than fibrocystic disease of the pancreas.

These results do not provide evidence that the carrier state in fibrocystic disease can be determined from raised levels of sweat sodium and chloride, nor that chest disorders in children show altered levels of these sweat electrolytes.

The 'sweat test' is of limited value in the diagnosis of fibrocystic disease of the pancreas in young adults or older persons.

Generalizations regarding genetic constitution in families of fibrocystic children should await further knowledge of the normal mechanism of control of sweat electrolytes and the basic defect in fibrocystic disease.

We should like to thank Miss R. Thomson for technical help with the electrolyte estimations, and Sister Pollock and her staff for help with the 'sweat tests', the many physicians of the Royal Children's Hospital who have referred patients to us, and the 'normal controls' who volunteered their help.

\section{REFERENCES}

Anderson, C. M. and Freeman. M. (1958) A simple method of sweat collection with analysis of electrolytes in patients with fibrocystic disease of the pancreas, and their families. Med. $J$. Aust., 1, 419.

Carter, C. O. (1953). In M. Bodian: Fibrocystic Disease of the Pancreas. Grune and Stratton, New York.

Childs, B. (1956). In Report of 18th Ross Pediatric Research Conference on Fibrocystic Disease of the Pancreas, p. 87 'Genetics'.

Darling, R. C., Di Sant' Agnese, P. A., Perera, G. A. and Andersen, D. H. (1953). Electrolyte abnormalities of the sweat in fibrocystic disease of the pancreas. Amer. J. med. Sci., 225, 67.

Di Sant'Agnese, P. A. (1957). Exocrine gland dysfunction in cystic fibrosis of the pancreas. Acta paediatr., Stockh., 46, 51.

(1959). Recent observations on pathogenesis of cystic fibrosis of the pancreas. Pediatrics, 24, 313.

_- Darling, R. C., Perera, G. A. and Shea, E. (1953). Sweat electrolyte disturbances associated with childhood pancreatic disease. Amer. J. Med., 15, 777.

Hsia, D. Y-Y., Driscoil, S. G., Greenberg, D., Lee, T-C. and Lanoff, G. (1958). Abnormal sweat electrolytes in patients with allergies. A.M.A. J. Dis. Child., 96, 685.

Kuno, Y. (1956). Human Perspiration. Thomas, Springfield, Illinois.

Petersen, E. M. (1959). Consideration of cystic fibrosis in adults with a study of sweat electrolyte values. J. Amer. med. Ass., 171, 1 .

Robinson, S. and Robinson, A. H. (1954). Chemical composition of sweat. Physiol. Rev., 34, 202.

Shwachman, H. and Leubner, H. (1955). In Advances in Pediatrics, p. 297. Year Book Publishers, Chicago.

Smoller, M. and Hsia. D. Y-Y. (1959). Studies on the genetic mechanism of cystic fibrosis of the pancreas. A.M.A. J. Dis. Child., 98, 277.

Wood, J. A., Fishman, A. P., Reemtsma, K., Barker, H. G., Di Sant' Agnese, P. A. (1959) A comparison of sweat chlorides and intestinal fat absorption in chronic obstructive pulmonary emphysema and fibrocystic disease of the pancreas. New Engl. J. Med., 260951. 